\title{
Correlation Between Outgoing Longwave Radiation and Surface Temperature in the Tropical Pacific: A Model Interpretation
}

\author{
Curt Covey \\ PCMDI \\ Lawrence Livermore National Laboratory \\ Livermore, CA 94551
}

\section{RECEIVED \\ JUL 221996 \\ OSTI}

November 1995

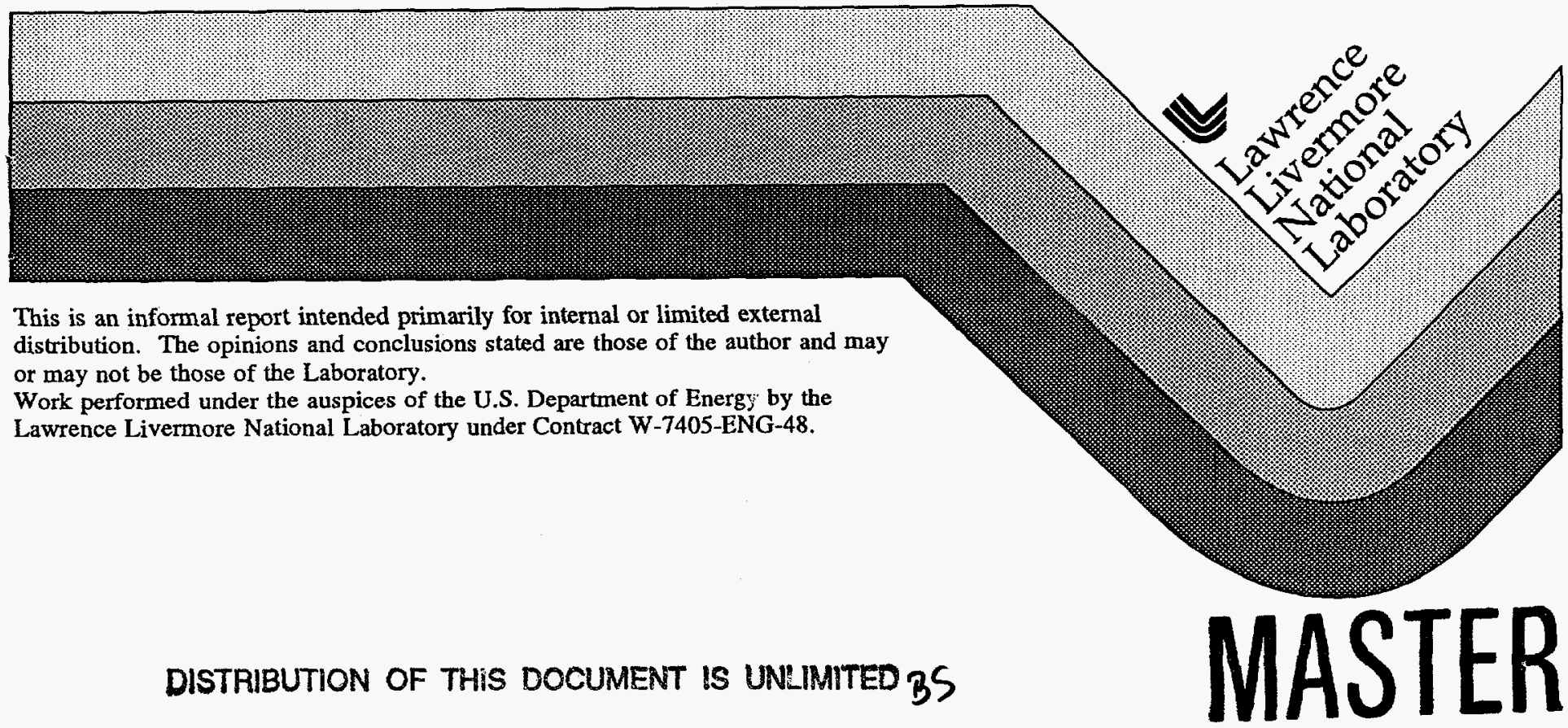




\section{DISCLAIMER}

This document was prepared as an account of work sponsored by an agency of the United States Government. Neither the United States Government nor the University of California nor any of their employees, makes any warranty, express or implied, or assumes any legal liability or responsibility for the accuracy, completeness, or usefulness of any information, apparatus, product, or process disclosed, or represents that its use would not infringe privately owned rights. Reference herein to any specific commercial product, process, or service by trade name, trademark, manufacturer, or otherwise, does not necessarily constitute or imply its endorsement, recommendation, or favoring by the United States Government or the University of California. The views and opinions of authors expressed herein do not necessarily state or reflect those of the United States Government or the University of California, and shall not be used for advertising or product endorsement purposes.

This report has been reproduced directly from the best available copy.

Available to DOE and DOE contractors from the Office of Scientific and Technical Information P.O. Box 62, Oak Ridge, TN 37831

Prices available from (615) 576-8401, FTS 626-8401

Available to the public from the

National Technical Information Service

U.S. Department of Commerce

5285 Port Royal Rd.,

Springfield, VA 22161 


\section{DISCLAIMER}

Portions of this document may be illegible in electronic image products. Images are produced from the best available original document. 



\section{ABSTRACT}

Results from the Atmospheric Model Intercomparison Project show that atmospheric general circulation models tend to underestimate the emission of anomalous heat to space during the 1987 El Niño episode in the tropical Pacific. This systematic bias implies that the models are underestimating negative feedbacks on climate that involve longwave radiation in the tropical atmosphere. These results are consistent with analyses of paleo-data that suggest climate models generally overestimate climate sensitivity in the tropics. 


\section{Introduction}

A recent paper by M.-D. Chou (1994) provides observational data that may be related to Earth's climate sensitivity (e.g., the global changes expected from human production of carbon dioxide, aerosols, etc.). Using the Earth Radiation Budget Experiment data set, Chou examined the correlation between outgoing radiation at the top of the atmosphere and changes in climate during an El Niño episode. He concluded that his "results are consistent with [R. S.] Lindzen's hypothesis that reduced upper-tropospheric water vapor in the vicinity of the enhanced convection region produces cooling that counteracts warming in the Tropics." Lindzen $(1990,1994)$ has used this hypothesis to argue against the idea that positive water-vapor feedback amplifies the sensitivity of the climate. Chou's observations may thus pose a challenge to conventional-wisdom estimates of future global warming such as those given by the Intergovernmental Panel on Climatic Change (Houghton et al., 1990).

The simplest quantitative perspective on this controversy is obtained by considering a hypothetical planet that radiates to space as a blackbody with uniform surface temperature $T$ (Hansen et al., 1981). Suppose the rate of energy input to the surface-atmosphere system increases by $\Delta Q$ Watts per square meter. The temperature would then increase to a new equilibrium value given by $\Delta\left(\sigma \mathrm{T}^{4}\right)=\Delta \mathrm{Q}$, where $\sigma$ is the Stefan-Boltzmann Constant. For a doubling of atmospheric $\mathrm{CO}_{2}, \Delta \mathrm{Q} \sim 4 \mathrm{~W} \mathrm{~m}^{-2}$ (Houghton et al., 1990). Using $\mathrm{T} \sim$ $255 \mathrm{~K}$ (the effective radiating temperature of Earth), one obtains $\Delta \mathrm{T} \sim 1 \mathrm{~K}$. General circulation models, however, typically obtain globally averaged $\Delta \mathrm{T}$ values considerably in excess of $1 \mathrm{~K}$ after $\mathrm{CO}_{2}$ doubling. In the models, atmospheric water vapor increases as global temperatures rise; the relative humidity stays roughly constant so that the absolute humidity increases. Increased water vapor, in turn, adds to the greenhouse trapping of outgoing 
longwave radiation. This positive water-vapor feedback enhances the original warming.

Chou's analysis related (among other things) changes in outgoing longwave radiation at the top of the atmosphere and changes in surface temperature, during natural fluctuations of the climate. His results apply only to the tropical Pacific $\left(30^{\circ} \mathrm{S}-30^{\circ} \mathrm{N}, 100^{\circ} \mathrm{E}-100^{\circ} \mathrm{W}\right)$. Changes in globally averaged OLR and globally averaged surface temperatures are too small during interannual climate fluctuations to form a reliable correlation. In the tropical Pacific, however, large changes in OLR and sea surface temperature are associated with the El Niño phenomenon. Chou compared an El Niño time, April 1987, to a non-El Niño time, April 1985. He found that areaaveraged tropical Pacific SST was $0.3 \mathrm{~K}$ warmer, and area-averaged tropical Pacific OLR was $6.8 \mathrm{~W} \mathrm{~m}^{-2}$ greater, at the El Niño time. But substituting $\mathrm{T}$ $300 \mathrm{~K}$ into $4 \sigma \mathrm{T}^{3} \times(0.3 \mathrm{~K})$ gives less than $2 \mathrm{~W} \mathrm{~m}^{-2}$. One may conclude that the real tropical Pacific atmosphere rejects the excess surface heat of El Niño to space more readily than a simple blackbody model would suggest-rather than less readily, as might be expected under the hypothesis of positive water vapor feedback.

The relationship between the mechanisms responsible for OLR changes in El Niño and the mechanisms operating in longer-term global changes, such as global warming, are no doubt complex. It is not my purpose here to investigate that relationship. Nevertheless, a natural question arising from Chou's observations is: to what extent are atmospheric GCMs able to reproduce them? That is the subject of this Note.

\section{AMIP model results}

The Atmospheric Model Intercomparison Project (Gates, 1992) provides a data base of output from 30 atmospheric GCMs run under identical boundary conditions. The boundary conditions include monthly mean SSTs 
observed for the period 1979-1988, covering the time periods examined by Chou. Of the 30 AMIP models, 29 include OLR in their output. I have examined the changes in tropical Pacific OLR between April 1985 and April 1987 for these 29 models, and I summarize the results in Table 1 and Figure 1. OLR arising from the combination of clear and cloudy skies that a model simulates in the normal course of its integration is hereinafter designated "total-sky OLR." In addition, I include for 13 models the OLR arising from only the clear-sky portions of each area element. I obtained the models' clearsky OLR from cloud radiative forcing calculated by Potter and Fiorino (1995). The Table and Figure also include the observed total-sky and clear-sky numbers from ERBE.

The average change (April 1987 minus April 1985) in total-sky tropical Pacific OLR for the models is $3.4 \mathrm{~W} \mathrm{~m}^{-2}$, about half the value observed. (The observed value given in the Table is $3 \%$ different from Chou's, apparently because I included land as well as ocean areas in the domain $30^{\circ} \mathrm{S}-30^{\circ} \mathrm{N}, 100^{\circ} \mathrm{E}-$ $100^{\circ} \mathrm{W}$ when averaging both model output and ERBE data.) The standard deviation of the model total-sky values is $2.9 \mathrm{~W} \mathrm{~m}^{-2}$. For clear-sky data, the model-average change in OLR is $2.3 \mathrm{~W} \mathrm{~m}^{-2}$, between two-thirds and threefourths the value observed, and the standard deviation is $1.3 \mathrm{~W} \mathrm{~m}^{-2}$. For both total- and clear-sky data, application of standard "twice-sigma" error bars to the model average would produce a range that includes the observed value in the range of model results. There seems little doubt, however, that the models exhibit a systematic bias of not enough increase in OLR. This point is made by Figure 1, a histogram of the results shown in Table 1. For total-sky data, all models except one obtain $\Delta(\mathrm{OLR})$ values less than observed. Note that the one model obtaining greater total-sky $\Delta(\mathrm{OLR})$ values than observed gets values far in excess of observations. The extreme positions of such "outliers" do not affect the model-median 'total-sky and clear-sky $\Delta$ (OLR) values. These are even smaller than the models' mean values: 2.9 and $1.8 \mathrm{~W}$ $\mathrm{m}^{-2}$ for total- and clear-sky respectively. A related statistic implying a 
systematic model underestimate of $\triangle(O L R)$ is the following: among the models, 18 of 29 get less than half the total-sky value observed, and 6 of 13 get less than half the clear-sky value observed.

The mechanism behind the changes in area-averaged tropical Pacific OLR is not a simple one. Figures 2 and 3 make this point for total- and clearsky data respectively, by comparing a sample of model results with observations in latitude-longitude space. As noted by Chou, the observed total-sky $\Delta$ (OLR) consists of both positive and negative values in the tropical Pacific domain (Fig. 2, top left). Observed OLR was less during the El Niño in the central and eastern equatorial Pacific, but it was greater during the El Niño at $\sim 20^{\circ} \mathrm{N}$ and in the western equatorial Pacific. Chou showed that these changes in OLR were associated with changes in cloudiness as equatorial convection shifted eastward and the Northern Hemisphere Hadley circulation strengthened during the $1987 \mathrm{El} \mathrm{Niño.} \mathrm{Cancellation} \mathrm{of} \mathrm{positive}$ and negative values of $\Delta(\mathrm{OLR})$, with magnitudes approaching $70 \mathrm{~W} \mathrm{~m}^{-2}$, results in an area-averaged observed value of about $7 \mathrm{~W} \mathrm{~m}^{-2}$.

In the models, the same qualitative pattern of total-sky $\Delta(O L R)$ also leads to extensive cancellation of positive and negative values in areaaveraging. The top right portion of Figure 2 shows a longitude-latitude map of an average over the models (restricted to the 13 models for which clear-sky data was also available, to facilitate comparison with Figure 3). The average over models shows the same pattern observed by ERBE: enhanced El Niño OLR in the subtropics and the western equatorial Pacific, and reduced El Niño OLR in the central and eastern equatorial Pacific. The magnitudes of both positive and negative $\Delta(O L R)$ are generally less than observed. Results from the two particular models whose area average total-sky $\Delta(\mathrm{OLR})$ was closest to that observed are shown in the bottom two frames of Figure 2. For one of these two models, ECMWF, the magnitudes of positive and negative $\triangle(O L R)$ are substantially greater than observed. In a root-mean-square sense the "average" model probably agrees better with the observations. For the other 
of the two models shown, CSU, agreement with observations is good in both an area-mean and root-mean-square sense.

Similar comments apply to clear-sky data, shown in Figure 3. Both observed and model-simulated quantities exhibit the general spatial pattern of positive and negative $\Delta(O L R)$ values described above for total-sky data. Again the average over models shows more muted positive and negative extremes than observed, and a smaller residual area-averaged value than observed. The two particular models whose area-average clear-sky $\Delta$ (OLR) was closest to that observed, MPI and UKMO, both obtain extremes of positive and negative values that are substantially greater in magnitude than observed.

\section{Discussion}

In exploring OLR changes and surface temperature changes between El Niño and non-El Niño times, Chou (1994) added to an observational data base that has been used to infer Earth's climate sensitivity. Earlier work correlated OLR variations in latitude, longitude, and season with corresponding surface temperature variations (Warren and Schneider, 1979; Raval and Ramanathan, 1989; Rind et al., 1991). These earlier studies revealed strong correlation between $\Delta($ OLR $)$ and $\Delta(S S T)$ with a slope in the neighborhood of 2 $\mathrm{W} \mathrm{m}^{-2} \mathrm{~K}^{-1}$. (Data associated with high surface temperatures in a limited area of the tropics is an exception to this rule: see Ramanathan and Collins, 1991.)

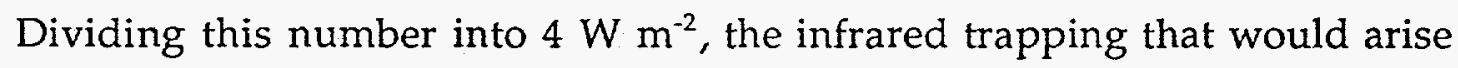
from an instantaneous doubling of atmospheric carbon dioxide, gives $2 \mathrm{~K}$. As noted in the Introduction, this simple arithmetic has long been cited to interpret GCM estimates of globally averaged equilibrium warming due to doubled $\mathrm{CO}_{2}$ (e.g., Hansen et al., 1981). Chou's data, however, imply $\Delta$ (OLR) / $\Delta(\mathrm{SST}) \sim 7 \mathrm{~W} \mathrm{~m}^{-2} / 0.3 \mathrm{~K}$, an order of magnitude larger than that obtained in the earlier studies. On its face this implies a climate sensitivity an order of 
magnitude smaller than conventional wisdom would claim, at least in the tropics.

Of course there is no guarantee that any of the foregoing correlations of $\Delta(\mathrm{OLR})$ with $\Delta(\mathrm{SST})$ is a reliable indicator of Earth's response to globally averaged climate forcing such as increased atmospheric $\mathrm{CO}_{2}$. Sun and Lindzen (1993) argued that comparison of individual points, or individual latitudes, with each other mainly reveals differences between the rising and sinking branches of the Hadley circulation. Analogous caveats apply to the interpretation of Chou's work. El Niño years are characterized by changes in horizontal SST gradients and a strengthened Hadley circulation (Pan and Oort, 1983); these phenomena may not be good proxies for global warming scenarios. For example, the GISS GCM predicts drying and enhanced OLR in the subtropics during El Niño years, consistent with the "average model" results shown in Figures 2-3. If it is forced by a globally uniform increase in either SST or atmospheric $\mathrm{CO}_{2}$, however, the GISS model responds in the opposite way. Absolute humidity increases, trapping more longwave radiation (A. D. Del Genio, personal communication).

Despite these cautionary notes, it is striking that virtually all of the AMIP models obtain changes in area-averaged tropical Pacific OLR that are substantially less than the observed values. The GCMs' area-averaged totalsky $\Delta(O L R)$ is typically greater than expected for a simple blackbody model, $4 \sigma \mathrm{T}^{3} \times(0.3 \mathrm{~K}) \sim 1-2 \mathrm{~K}$, but it is not large enough to match observations. The direction of the bias means that the GCMs are underestimating the ability of the tropical atmosphere to reject excess heat to space. Such an effect is consistent with paleo-data that implies GCMs overestimate climate sensitivity in the tropics (see Covey et al., 1995, for a brief review).

It is beyond the scope of this Note to elucidate the mechanisms behind the models' behavior. Some preliminary remarks follow, however, from comparing the total- and clear-sky data. Consider only the 13 models in Table 1 for which clear-sky output is available. The average, over the 13 models, of 
area-averaged $\Delta(\mathrm{OLR})$ is about $30 \%$ less than the observed area-averaged $\Delta$ (OLR) for both total- and clear-sky data. Also for these 13 models, the correlation between total- and clear-sky area-averaged $\Delta(O L R)$ is 0.96 . Even though changes in OLR during El Niño years are associated with shifts in cloudiness, the source of model errors appears to involve clear-sky processes as well.

Acknowledgements. I am grateful to R. S. Lindzen for drawing my attention to Chou's observations. Data processing and graphics were accomplished with the Visualization and Comptation System, and associated software, written by Dean Williams, Bob Mobley, Bob Drach and Karl Taylor. This work was performed under auspices of the U. S. Department of Energy by the Lawrence Livermore National Laboratory under Contract No. W-7405Eng-48. 


\section{REFERENCES}

Chou, M.-D., 1994: Coolness in the tropical Pacific during an El Niño episode. J. Climate, 7, 1684-1692.

Covey, C., L. C. Sloan, and M. I. Hoffert, 1995: Paleoclimate data constraints on climate sensitivity: The paleocalibration method, Climatic Change, in press.

Gates, W. L., 1992: AMIP: The Atmospheric Model Intercomparison Project, Bull. Amer. Met. Soc., 73, 1962-1970.

Hansen, J., D. Johnson, A. Lacis, S. Lebedeff, P. Lee, D. Rind, and G. Russell, 1981: Climatic impact of increasing atmospheric carbon dioxide, Science, 213, 957-966.

Houghton, J. T., G. J. Jenkins, and J. J. Ephraums (eds.), 1990: Climate Change: The IPCC Scientific Assessment, Cambridge University Press, Cambridge.

Lindzen, R. S., 1990: Some coolness concerning global warming. Bull. Amer. Meteor. Soc., 71, 288-299.

Lindzen, R. S., 1994: Climate dynamics and global change. Ann. Rev. Fluid Mech., 26, 353-378.

Pan, Y. H., and A. H. Oort, 1983: Global climate variations connected with sea surface temperature anomalies in the eastern equatorial Pacific Ocean for the 1958-1973 period, Month. Weath. Rev., 111, 1244-1258. 
Phillips, T. J., 1994: A Summary Documentation of the AMIP Models, PCMDI Report No. 18, Program for Climate Diagnosis and Intercomparison, LLNL, Livermore, CA.

Potter, G. L., and M. Fiorino, 1995: The Atmospheric Model Intercomparison Project (AMIP) diagnostic subproject on cloud radiative forcing, in Proceedings of the First International AMIP Conference (15-19 May 1995, Monterey, CA), WCRP Report No. -, World Meteorological Organization, Geneva, in press.

Raval, A., and V. Ramanathan, 1989: Observational determination of the greenhouse effect, Nature 342, 758-762.

Ramanathan, V., and W. Collins, 1991: Thermodynamic regulation of ocean warming by cirrus clouds deduced from observations of the 1987 El Niño, Nature 351, 27-32.

Rind, D., E.-W. Chiou, W. Chu, J. Larsen, S. Oltmans, J. Lerner, M. P. McCormick, and L. McMaster, 1991: Positive water vapor feedback in climate models confirmed by satellite data, Nature 349, 500-503.

Sun, D.-Z., and R. S. Lindzen, 1993: Distribution of tropical tropospheric water vapor, J. Atmos. Sci. 50, 1644-1659.

Warren, S. G., and S. H. Schneider, 1979: Seasonal simulation as a test for uncertainties in the parameterizations of a Budyko-Sellers zonal climate model, J. Atmos. Sci. 36, 1377-1391. 
Table 1: April 1987 Minus April 1985 OLR, Averaged over the Tropical Pacific $\left(30^{\circ} \mathrm{S}-30^{\circ} \mathrm{N}, 100^{\circ} \mathrm{E}-100^{\circ} \mathrm{W}\right)$

\begin{tabular}{|c|c|c|}
\hline Model Name & Total-Sky $\Delta(\mathrm{OLR})\left[\mathrm{W} / \mathrm{m}^{2}\right]$ & Clear-Sky $\Delta(\mathrm{OLR})\left[\mathrm{W} / \mathrm{m}^{2}\right]$ \\
\hline BMRC & 2.94 & 1.49 \\
\hline CCC & 2.02 & \\
\hline CNRM & 5.43 & \\
\hline COLA & 3.17 & 1.46 \\
\hline CSIRO & 3.67 & 1.76 \\
\hline CSU & 6.22 & 1.15 \\
\hline DERF & 3.07 & \\
\hline DNM & 1.51 & 2.26 \\
\hline ECMWF & 5.99 & 1.92 \\
\hline GFDL & 3.45 & \\
\hline GISS & 3.67 & \\
\hline GLA & 2.90 & 0.72 \\
\hline GSFC & 2.21 & 3.58 \\
\hline IAP & 1.81 & \\
\hline JMA & 5.41 & 1.31 \\
\hline LMD & 0.42 & \\
\hline MGO & 1.79 & \\
\hline MPI & 5.45 & \\
\hline MRI & 0.06 & 3.43 \\
\hline NCAR & 2.17 & \\
\hline NMC & 2.49 & 3.19 \\
\hline NRL & -3.55 & \\
\hline SUNYA & 5.10 & \\
\hline SUNY/GENESIS & 6.18 & \\
\hline UCLA & 1.63 & \\
\hline UGAMP & 14.02 & \\
\hline UIUC & 2.39 & \\
\hline UKMO & 5.97 & \\
\hline YONU & 2.17 & \\
\hline Model Average & $3.44^{b}$ & \\
\hline ERBE (observed $)$ & 7.03 & \\
\hline & & \\
\hline
\end{tabular}

aSee Phillips (1994) for extensive model descriptions.

${ }^{b}$ Average over models for which clear-sky output is available $=4.55 \mathrm{~W} \mathrm{~m}^{-2}$. 


\section{FIGURE CAPTIONS}

FIG. 1. Histogram of the results given in Table 1 .

FIG. 2. April 1987 minus April 1985 total-sky outgoing longwave radiation [W $\left.\mathrm{m}^{-2}\right]$ in the tropical Pacific. Top left: observed by the Earth Radiation Budget Experiment. Top right: simulated by an average of AMIP models (all models for which clear-sky results are also available). Bottom frames: simulated by the two particular AMIP models whose area-averaged results are closest to observed.

FIG. 3. Same as Fig. 2 for clear-sky outgoing longwave radiation (note the change in color scale). 


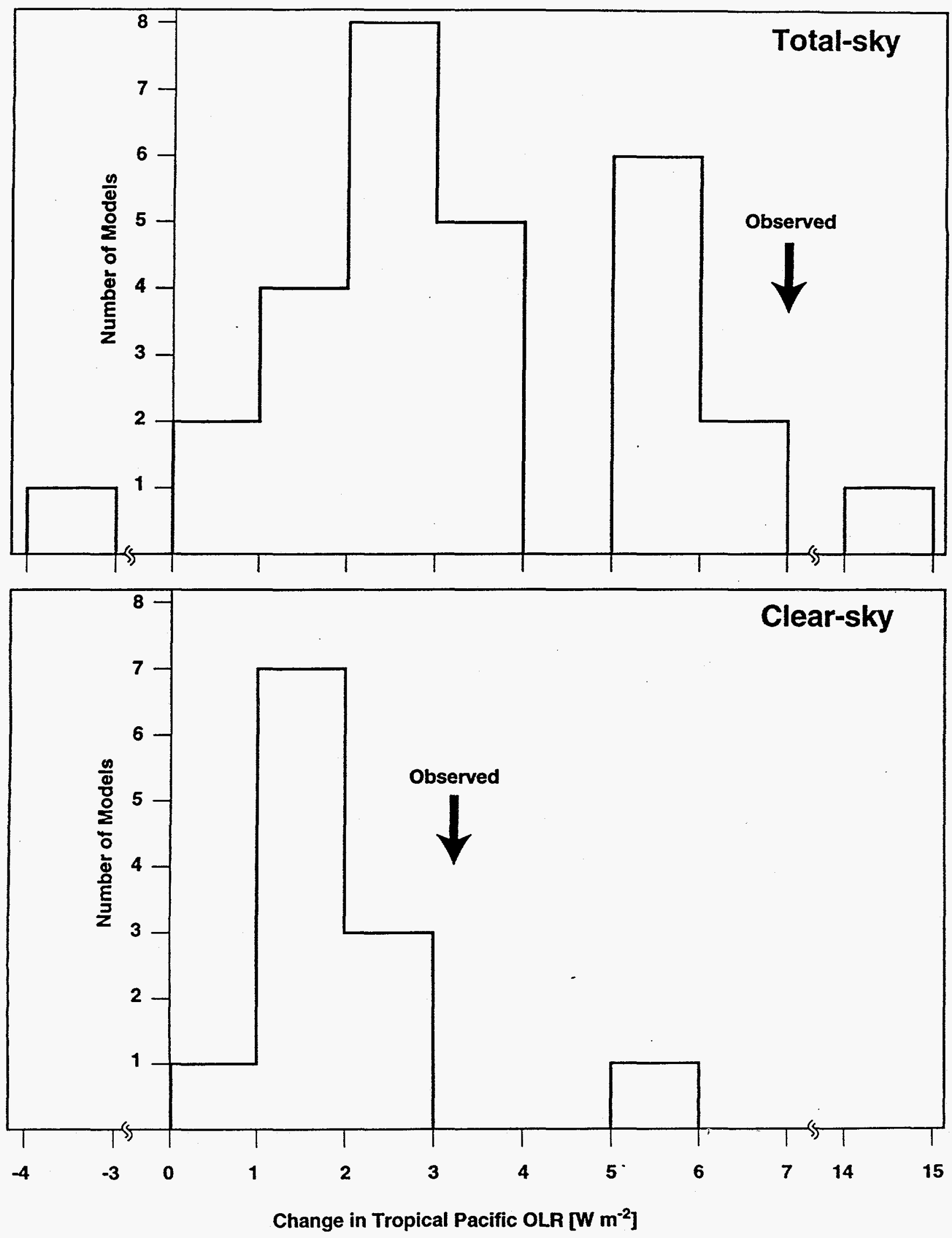


Figure 2

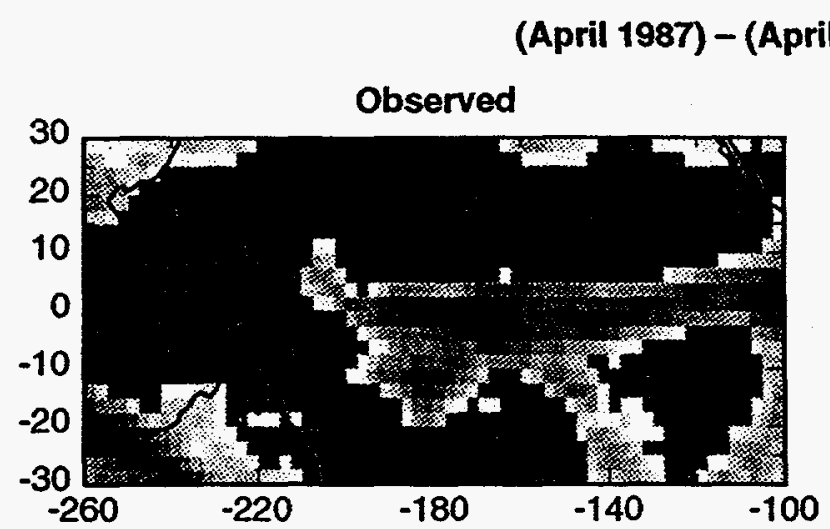

1985) OLR $\left[\mathrm{W} \mathrm{m}^{-2}\right]$
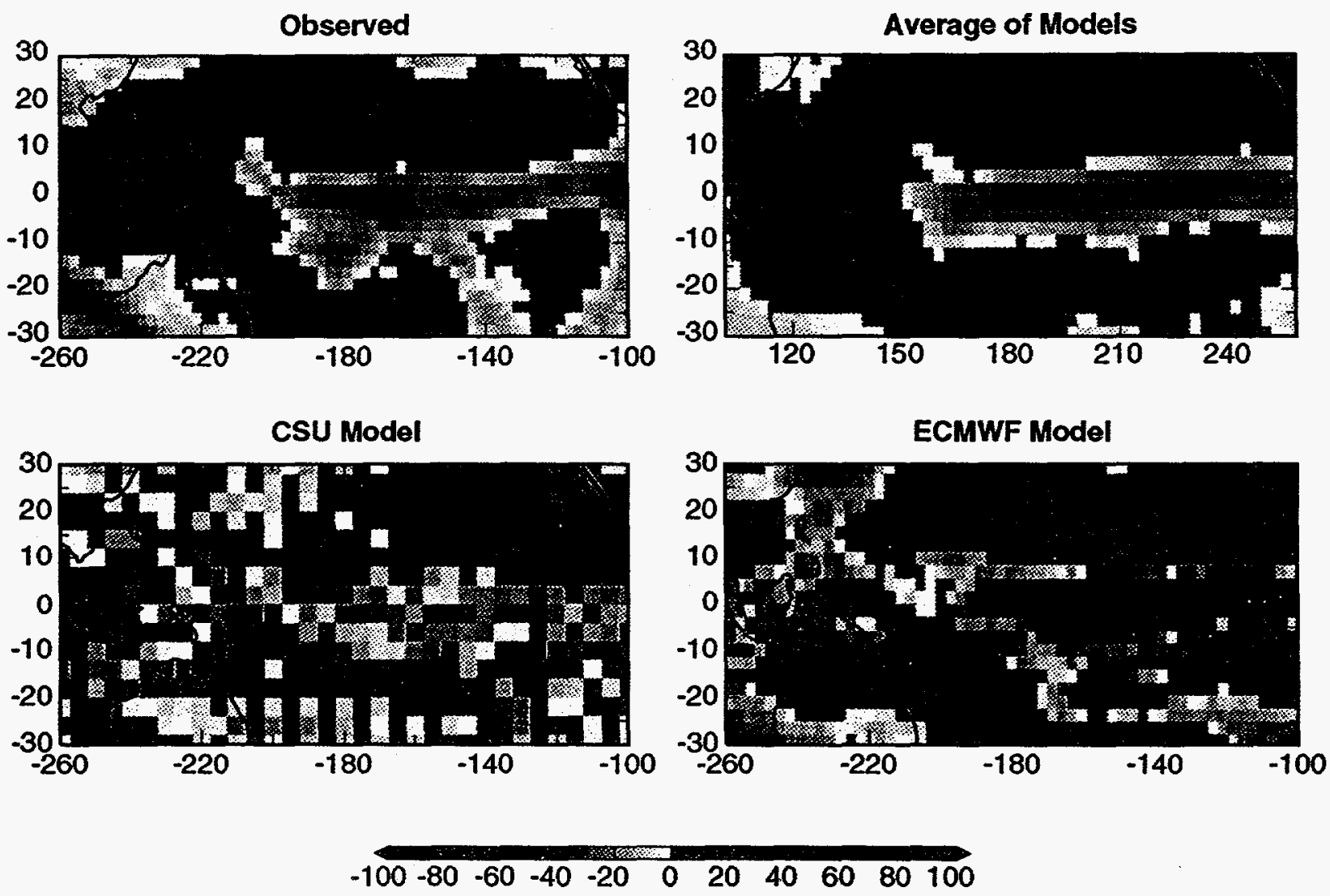
Figure 3

(April 1987) - (April 1985) Clear-sky OLR $\left[\mathrm{W} \mathrm{m}^{-2}\right]$
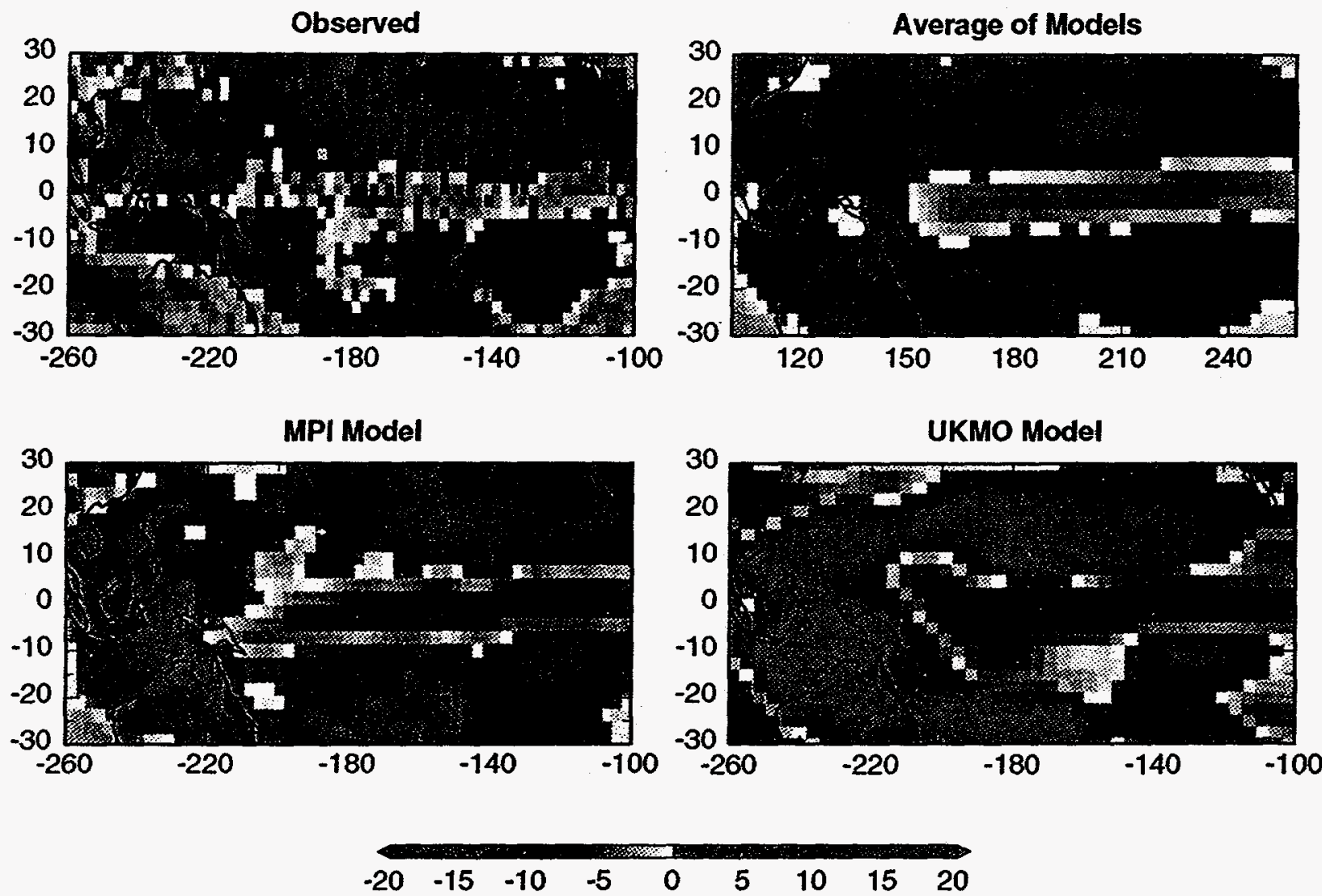